Australian Journal of

Educational Technology

\title{
Analysing cognitions in a hypermedia learning environment
}

\author{
David Frampton \\ Division of Information Services \\ Griffith University \\ Brisbane, Australia
}

\begin{abstract}
The paper describes the theoretical basis and methodology for research seeking to identify higher order cognitive activity occurring in students' information seeking and learning tasks with hypermedia. It reviews difficulties arising from the inconsistency among schemes of cognitive analysis, and of articulating such schemes closely with accounts of the desirable attributes of graduates in employment, where the display of higher order skills is expected. It concludes that such analyses of learning with hypermedia must, despite these problems, be guided by more holistic theoretical accounts of thinking, and constantly adapt methodologies to avoid reliance on over-simplified models.
\end{abstract}

\section{Technology and thinking: Tracking the relationships}

\section{A focus on learning with hypermedia}

A research project at Griffith University, Cognitive Processing in Hypermedia Settings (Alexander and Frampton 1993, 1994) has investigated the incidence of categories of thinking among users of hypermedia applications. Our primary interest has been in student learning from multimedia and hypermedia, so the possible relationships between the nature and features of these technologies and students' thinking needed to be revealed and understood as clearly as possible, because good thinking is necessarily an important outcome for universities.

This entailed due consideration of higher education's current concern with the generic, transferable cognitive capacities ideally desired of graduates, and with the means of aligning the development of these capacities in the course of undergraduate studies with lifelong learning approaches and professional attributes and attitudes valued in employment. 


\section{Problems of method}

Consequently, adopting an appropriate mode of accounting for cognitive processes evident in the video recorded observations of learners interacting with multimedia products required facing a number of theoretical and methodological problems:

- Reconciling available classifications of thinking, conflicting views of generic, transferable cognitive skills in graduates and the strongly context specific character of much higher order thinking performance.

- Questions concerning the degree of separateness of technologies like hypermedia from both the knowledge domain which they mediate and the cognitive activities which define or instrumentalise that mediation.

- Mismatches between the apparent advantages of using the multisensory channels offered by hypermedia and multimedia applications and the conventional heavy concentration of cognitive process descriptions on abstract symbolic manipulation.

- Acquiring meaningful observation data from interactions divorced from the mainstream context of the students' course and learning environment.

From our point of view, the project needed to map out a course towards better process descriptions and categories which would take account of these problems as far as possible. We therefore give considerable prominence in this paper to the theoretical and empirical positions which affect that trajectory.

\section{Thinking: Current dilemmas}

\section{Mismatches between classifications of thinking}

There are three contexts relevant to our research in which cognitive performance is either a highly significant or determining factor: (a) the context of teaching thinking skills, whether as detached cognitive frameworks or as embedded in a knowledge domain, (b) the context of current discussions, debates and data concerning the attributes and performances of graduates in employment, and particularly the designation of those performances as examples of 'higher order' thinking, (c) the context of empirical and theoretical research concerning the relationship between intelligent technologies and cognition.

It is instructive to compare features of schemes for the description of thinking and for prescriptive use in teaching it, such as those presented by Bloom (1956), Sternberg (1986), Presseisen (1985) and Beyer (1988). Depending upon how one wishes to use these schemes, one may see them either as having substantial areas of overlap or as having disturbingly 
discrepant features. For example, Ross (1994) makes use of the Bloom taxonomy without modification for an experimental correlation with hypertext design. However, comparisons among the four illustrative classification schemes show that analysis and synthesis, which are ranked at the higher end of Bloom's scale, are nevertheless among Beyer's (1988) 'micro-thinking' skills which serve, but are not themselves examples of, the highest orders of thinking. Again, analysis and synthesis are among the lower order of 'basic processes' proposed by Presseisen (1985). Sternberg (1986), would not rank these skills directly among the higher-order 'metacomponents' of his own conceptual scheme.

The notion of critical thinking gives rise to similar problems. Beyer acknowledges the current relativist position that it means 'whatever its users stipulate it to mean' (1988:61). Critical thinking is generally regarded as a higher order skill more characteristic of experts than of novices. However, Pogrow (1985) states that he has found no evidence that mastery of basic thinking skills is a prerequisite for engaging in higher order thinking skills. On the contrary, he observes, evidence from animal research suggests that in fact higher order thinking proceeds independently of basic thinking tasks (1985:239). Glaser (1984) notes similarly that, although it is believed that higher thinking skills are complex and basic skills more rudimentary, just the reverse may in fact be the case.

\section{Purpose built adaptations}

Generally speaking, researchers and practitioners setting up experiments to track the incidence of various kinds of cognition in learning activities, with or without information technologies, use descriptions traceable in some way to the above and other well known classifications. Clements and Nastasi (1992), for example, use Sternberg's scheme in their studies of educational computing, while Ross (1994), as we have seen, seeks parallels between Bloom's taxonomy and designs for hypertext. Many authors describe specific contexts of learning involving information technology systems in terms of categories of cognition which might well, in the light of the kinds of differences illustrated above, have disparate features and lead to different interpretations of evidence depending on the scheme chosen (Hooper and Hannafin, 1991; Atkins and Blissett, 1992; Jonassen and Grabinger, 1989; Bransford et al, 1990; Misanchuk and Schwier, 1991; Kozma, 1991).

\section{The skills and attributes required of graduates}

We also turned our attention to the kinds of statements currently being made about what is required of graduates in professional occupations and industry. In relation to the USA, we can instance specific detailed attention to critical thinking commissioned by the Department of Education (Paul and Nesich, 1992), a relentless critique of the total failure of present systems to foresee the needs of the information age (Perelman, 1992), and 
advocacy of new paradigms of learning (Twigg, 1994). In Australia, various reports which have appeared in the context of the 'quality movement' have offered views on what should be expected of graduates emerging from university (Higher Education Council, 1992a, 1992b; Warren Piper, 1993; Higher Education Council/Australian ViceChancellors' Committee, 1994; Moses and Triwell, 1993).

These statements or reports of investigations have generally emphasised the need to cultivate deep as opposed to surface learning during undergraduate studies, in the sense in which these concepts have been developed and theorised over the past twenty years (Marton and Saljo, 1976; Entwhistle in Richardson et al, 1987; Entwhistle and Ramsden, 1982; Trigwell and Prosser, 1991). The concepts are illustrated by Entwhistle's 'defining features of approaches to learning', cited by Warren Piper (1993:133) as'work provid[ing] direct, clear and specific pointers for the creation of high quality educational regimes at university level':

Deep Approach. Intention to understand, vigorous interaction with content, relate new ideas to previous knowledge, relate concepts to everyday experience, relate evidence to conclusions, examine the logic of the argument

Surface Approach. Intention to complete task requirements, memorise information needed for assessments, failure to distinguish principles from examples, treat task as an external imposition, focus on discrete elements without integration, unreflectiveness about purpose or strategies.

Strategic Approaches. Intention to obtain highest possible grades, organise time and distribute effort to greatest effect, ensure conditions and materials for studying appropriate, use previous exam papers to predict questions, be alert to cues about marking schemes.

The outcome hoped for from these processes is typically expressed in a university mission. The following desired attributes of graduates are cited as an example by Warren Piper (1993).

Coherent and extensive knowledge in a discipline area

Ability to reason logically and distinguish fact from opinion

Appreciation of other cultures and customs

Clear and fluent communication in writing

Oral articulateness and confidence

Computer literacy

Statistical literacy

Valuing truthfulness, accuracy, honesty and ethical standards in personal and professional life 
Capacity to accept responsibilities and obligations as well as assert rights

A desire and the skills for continued intellectual development and creativity

\section{Different discourses, different understandings}

The decisive points of articulation among the various components of cognitive activity in the classifications of thinking, purpose built adaptations for technology supported environments, and the holistically described attributes required of graduates, are not readily apparent. Any meaningful discussion of the integral role of information technologies in cognition must be affected by how we approach this question of articulating its components, which have often been viewed as 'packets of information that could be acquired piecemeal' (Royer, Cisero and Caro, 1993), with the broadly defined cognitive attributes of educated individuals and groups in society.

The ambiguities which abound in these divergent discourses on cognition have been strongly influenced by concepts of situated and distributed cognition (Lave, 1988; Brown, Collins and Duguid, 1989; Salomon, 1993; Pea, 1992; Schank and Birnbaum, 1992). Such ambiguities can be found within the same document. Penington asserts, for example, in a discussion paper on undergraduate education (Higher Education Council/ Australian Vice-Chancellors' Committee, 1994) that the notion of transferable generic skills is not proven and does not withstand rigorous intellectual testing, while the document notes that this assertion seems to run counter to the observation, experience and expectations of employers of graduates.

It is not unfair to assume that the object of discourse (generic, higher order, transferable cognitive abilities) has different meanings to the different stakeholders who have a concern for the cognitive performance of graduates in work and social roles, and for the means of helping them to achieve it. There would appear to be a fairly fundamental contradiction between, on the one hand, the project of shifting the preoccupations of higher education from a fixation with content coverage to enabling students to become lifelong learners, and, on the other, evidence that the highest cognitive performances emerge from the most intensively contextualised and knowledge dependent activities (Royer, Cisero and Caro, 1993; Glaser, 1984;Greeno, 1989; Schank and Birnbaum, 1992; Pea, 1987b). Seemingly, you cannot have it both ways.

\section{Universal categories of cognitive skill and situated cognition}

Much hinges on the extent to which some core of cognitive activity can be conceived of as universal and generalisable, and, if so, in what ways. There has been a progressive deconstruction of the ideal of supposedly context free, logico-mathematical or symbolic thinking (Gardner, 1983; Pea, 1987a; Lave, 1988; O'Loughlin, 1992), the prominence of which has 
been attributed largely to the influence of Piaget, and of the central role of generalised, transferable cognitive strategies or heuristics (Perkins and Salomon, 1989), in favour of the alternative proposition that 'all learning is contextual' (Department of Employment, Education and Training, 1994). Kay (1993/4), for example, acknowledges that the field of research into human-computer interaction has been disserved by a lack of attention to context, and that Aristotelian rationality is too neat and too structured to cohere with the kinds of diversity encountered in real life.

Perkins, Jay and Tishman,(1993), addressing this dilemma, argue for a much more complex and holistic conception of 'mindware' (they use this neologism to avoid the conceptual frameworks referred to above) capable of accommodating this diversity. Research has produced, in their view, 'an enriched entology of mind, a more panoramic picture of the kinds of mindware that figure importantly in thinking'. They seek a compact between the contending positions of context-free and context-bound cognition, but emphasise all the same that any acceptable account of good thinking must take due account of research in cognition and recognise 'the power of the particular'. As Kay (1993/4) notes, coming round to this position means overcoming the traditional scientific view that universality is inherently more meaningful than diversity.

This direction is supported in an overview by McGuiness (1993) of research and practice associated with teaching thinking. She argues for a 'cognitive apprenticeship' model, and cites Greeno's (1989) case for adopting new perspectives which question a number of framing assumptions, namely: 'that thinking is about individual mental representations; that cognitive processes are uniform across people and situations; and that knowledge and skills are built up from simple component processes'.

\section{The force of the cultural argument}

The important issue here is that the erosion of the central position of universal or generalisable categories in accounts of thinking and intelligence goes hand in hand with the force of culture-specific explanations of cognition.

Paul and Nesich's (1992) proposed model for the national assessment of higher order thinking in the United States postulates 'universal intellectual standards' as one of the four domains essential to critical thinking. This 'universalism' exhibits a contemporary flavour in the requirement that the process of assessment should 'respect cultural diversity by focusing on the common core skills, abilities and traits useful in all cultures', but at the same time, of course, both assumes the existence of a common core and appeals to an undefined criterion of 'usefulness'. Lave (1988) sees Western 
rationality more radically as the universalising formula allowing this system of thought to be both closed and tautologised endlessly (83), while Paul and Nesich's program can be viewed as perhaps going some way towards recognising the context-specific and culture-specific aspects of cognition.

In order to explain the substantial shift of perspective needed to view cognition and intelligence from the viewpoint of contemporary research, Schank and Birnbaum (1992) point to the traditional psychological preconception that the knowledge base of intelligence is 'too contingent, too atomised, too undifferentiated' to be other than 'grist for the mill' as far as theories of cognition and intelligence are concerned. Hence, they argue, psychological theory has given serious attention only to the mill and largely ignored the grist. As Perkins and Salomon (1989) put the matter in relation to the neglected role of specific, culturally determined knowledge: 'There didn't seem to be enough to know about such databases to make them central to thinking ability'.

\section{Cognition and intelligence as emergent}

Situated cognition theory, with the emphasis it places on the substantial cultural determinants of cognition and socially intelligent behaviour, is strongly interrelated with theories of distributed intelligence and distributed cognition (Brown, Collins and Duguid, 1989; Pea, 1992; Schank and Birnbaum, 1992; Salomon, 1993).

One of the important implications of these parallel theoretical frameworks is that intelligence and cognition have to be seen as emergent processes rather than as fixed or variable quanta, and it is from this viewpoint that the role of technologies in learning can most productively be examined. As Pea (1985) observes: '... the specific restructurings of cognitive technologies are rarely predictable; they have emergent properties that come to be discovered only through their use'.

In a later article (1992) he asks: 'What opportunities are lost for learner participation in higher level activities, and meaningful contributions rather than basic skills practice, if one does not allow for distributed intelligence support for those activities involving artefacts and other persons?' The 'artefacts and other persons' are the social or learning ecology (Frampton and Wharton, 1992, 1993) designated as 'person-plus-surround' by Perkins (1993). Allowing for 'emergence' in the intelligent behaviour exhibited in technology supported environments is clearly at odds with the view of information and communications technologies as neutral carriers of 'content' (Clark, 1983), which is consistent with a logical positivist rather than a constructivist concept of enculturated knowledge. 


\section{Preliminary work on methodology}

In the foregoing, we have reviewed theoretical underpinnings for the interpretation of cognitive behaviours in hypermedia environments. We now discuss how this framework is influencing the way in which we believe such observations can best be structured.

Details of our preliminary analytical approaches have been reported elsewhere (Alexander and Frampton, 1992,1993). To recapitulate these briefly, having transcribed the 'events' both directly observed and recorded on videotape for the duration of a task undertaken separately by 15 pairs of subjects, the researchers applied the terms of classification schemes, either singly or using more than one at a time, to the transcribed verbal protocols of the learners' commentaries and the accompanying video recorded actions.

The terms were applied both to a 'content' column and to an 'interface' column of specially prepared logsheets while the researcher viewed the recorded events. The latter took the form of a view of the pairs of subjects (less than $25 \%$ of the screen area) inserted into a full screen view of the application in use.

The task set for the subjects in these preliminary observations was to search for and identify information related to a specific set of historical circumstances. The purpose was not to attempt to measure learning gains, which would have required different methods, but to categorise the cognitive performance evident within the boundaries of segments, and particularly to identify the incidence of higher order thinking.

Certain measures which we applied were relatively task specific (eg. time taken from start to first content related search activity, whether 'closure' was achieved). Quite wide variations were observed in some cases (eg. from 5 minutes to 32 minutes from start to 'first item of relevant information').

\section{Rowland's classification scheme}

The kinds of discrepancies discussed in the first part of this paper between different classifications of cognition became apparent in attempts to apply them to the recorded and transcribed protocols. Our preference for the type of analysis in question eventually favoured a classification scheme devised by Rowland (1992) to analyse the cognitive performances of novice and expert instructional designers going about a task. 
Rowland's principal terms are the following:

$\begin{array}{ll}\text { READ } & \text { PREDICT } \\ \text { REPHRASE } & \text { GENERATE } \\ \text { DESCRIBE } & \text { EVALUATE } \\ \text { RECORD } & \text { CITE REASON } \\ \text { RETRIEVE } & \text { CONCLUDE } \\ \text { QUESTION } & \text { REVIEW } \\ \text { IDENTIFY } & \text { STATE DOING } \\ \text { INFER } & \text { PLAN } \\ \text { [GOAL] } & \end{array}$

Each one is accompanied by a fuller description which has been omitted for simplicity. The description for 'IDENTIFY', for example, reads: 'label something as a (problem, constraint, resource, etc.) without certainty; can be a hypothesis; arrived at primarily through analysis of given and inferred in formation'.

The attractiveness of Rowland's largely non-hierarchical scheme lay not so much in its apparent simplicity compared with some of those we examined as in its specificity for the task and subtlety in the detail: with its main cognitive terms as operators, its application is never 'disembedded' from the task under study.

\section{Lessons learnt from preliminary observation and analysis}

Although there is no prima facie reason why higher order cognition should not be apparent in the type of observation we used for our preliminary work, we were unable to locate other than occasional possible instances, either in relation to specific segments of recorded events or in a more holistic overview of a complete session.

Our observation was that the subjects generally had an insufficient familiarity with the conceptual relationships proper to the domain (wars in which Australia had been involved in the twentieth century) for incidence of a deep or relational approach (Trigwell and Prosser, 1991) to be apparent. That view would of course tend to lend weight negatively to the robustness of situated cognition theory as it has been discussed above.

A second conclusion in which the researchers concurred was that the cognitive classification schemes examined did not appear to cater well for subjects' response to non-textual items in a multimedia environment. Presseisen (1985:44) noted that spatial or visual processing had been taking on increased significance in instruction, and touched on the question of its effect on cognitive development. However, she concluded that the testing of cognitive abilities already catered adequately for multiple modes of thinking. 
We tend to disagree ; with that view. In the comments column of our log sheets we noted some clear affective reactions to non-textual items, but in cases where, using Presseisen's classification of basic and complex skills, it was difficult to find the appropriate coding for these events. It is not clear, in our view, that current means of identifying cognitive events can adequately cater for responses to the organisation of media in a multimedia program, or for the emergent characteristics of distributed cognition in that environment. Evidence provided by Schwarz and Clore (1988) about the information function of affective states, for example, should warn us against assuming too readily that the types of classification discussed earlier in this paper are fully suitable for dealing with emergent technology supported cognitions.

Another problem we recognised was that of carrying out the observations separately from the students' overall learning environment and course context. Since we were not focusing on specific learning acquisitions but on the incidence of cognitive events, particularly of a higher order, in a multimedia computing environment, this aspect may arguably have been less important than specific task motivation and the lack of appropriate conceptual knowledge.

Even so, where practical organisation makes it difficult to study cognitive events in situ in closer accordance with ethnomethodological procedures, it seems to us useful to allow for some compensating features encouraging conation. Examples might be the close relevance of the content area of a multimedia product to the subjects' immediate academic concerns, or means of increasing extrinsic motivation towards the task or environment involved in the trial (unless, of course, motivation is one of the variables being gauged).

\section{Modifying the methodology}

In the light of the preliminary work and of the theoretical considerations discussed in the first part of this paper, we are modifying our methodology in a number of ways, while continuing to use the basic scheme devised by Rowland. We conclude with an indication of the main changes through which we are now working.

\section{Preparation of the problem 'space'}

It is reasonable to expect that multimedia resources for learning should be able to provide and shape challenging problem or task delineations. At the very least, if they do not incorporate explicit pedagogy, they should not frustrate an initially adequate level of motivation towards a task.

To compensate for the conduct of a fresh set of observations in an environment somewhat detached from the normal learning context, we have consequently spent considerable preparatory time with a third year 
$\mathrm{PhD}$ student in the subject area concerned in order to shape the most motivating problem complex. This student has been observed and video recorded addressing problems himself using the hypermedia product in question. He is evidently well beyond undergraduates in his developing expertise in the content domain, yet still close enough to the undergraduate course context to provide valuable input to the tasking process. However, we believe that this aspect of the research methodology merits further attention.

\section{Defining the grain size: Operators and 'conceptual objects'}

As noted, we found Rowland's close contextualisation of the cognitive events in his experiments very instructive. While we are adapting the terms of his classifications to suit the multimedia/hypermedia environment (eg in order to respond better to affective modes and visualisation), we are taking cognitive 'operators' (IDENTIFY, EVALUATE, etc) in conjunction with the 'conceptual objects' which they mediate to be synthetic 'wholes'.

In other words, we are resisting generalising from observed events that a particular subject can 'analyse', for example, observing only that she applies analysis to such-and-such a conceptual object or objects. We do not intend to assume transferability.

\section{Conceptual and interface objects: Better integration}

This approach will, we believe, allow for 'conceptual objects' and 'interface objects', while seemingly heterogeneous, to be presented in our analyses as elements on the same plane. This perspective on a cognition/technology environment or 'ecology' owes some of its theoretical framework to the philosopher Gilles Deleuze (particularly 1969,1993).

It is also coherent with theories of situated and distributed cognition discussed earlier, and emphasises the socially constructed interdependence of the endogenous and exogenous elements of technology mediated learning environments and communication: 'the resources that shape and enable activity are distributed in configuration across people, environment and situation. In other words, intelligence is accomplished rather than possessed' (Pea, 1992:3).

\section{A better accounting for deep and surface quality of cognitive events}

While we accept in general that it is difficult to seek appropriate characterisations of higher order cognition in classification schemes which purport to represent the molecular components of cognition (Royer, Cisero and Caro, 1993), we believe that a coding of events along the deep/surface dimension can provide valuable partial evidence of the quality of cognitions, with the same criteria being applied to students' postobservation reports on a problem solving task. 


\section{Visualisation and other hypermedia related factors}

We recognised that Rowland's (1992) scheme was fairly specific to the task he reported in his research. However, we are currently using it as a basis with the smallest number of modifications necessary to cater for our concerns. These include, provisionally, adding the operators LOOK, SELECT, SEARCH and SWITCH (ie. 'switch intellectual vehicles', an operator suggested by Jonassen and Grabinger, 1989), which will be accompanied, as are Rowland's other operators, by elaborations setting the limits of the operator's area of application.

\section{References}

Alexander, M. and Frampton, D. (1993). Student interactions with multimedia: Cognitive processing and user interface evaluation. In Ianella, R. (ed), Proceedings of the QCHI93 CHISIG (Qld) Symposium. Gold Coast, Australia: Bond University.

Alexander, M. and Frampton, D. (1994). Technology and thinking: A qualitative study with interactive multimedia products. In McBeath, C. and Atkinson, R. (eds), Proceedings of the 2nd International Interactive Multimedia Symposium. Perth: Promaco Conventions Pty Ltd.

Atkins, M. and Blissett, G. (1992). Interactive video and cognitive problem solving skills. Educational Technology, 32(1),44-50.

Beyer, B. (1988). Defining thinking and thinking skills: Practical strategies for the teaching of thinking. Boston: Allyn and Bacon.

Bloom, B. (ed) (1956). Taxonomy of educational objectives. New York: David McKay and Company Inc.

Bransford, J., Sherwood, R., Hasselbring, T., Kinzer, C. and Williams, S. (1990). Anchored instruction: Why we need it and how technology can help. In Nix, D. and Spiro, R. (eds), Cognition, education and multimedia. Hillsdale, NJ: Lawrence Erlbaum.

Brown, J., Collins, A. and Duguid, P. (1989). Situated cognition and the culture of learning. Educational Researcher, 18(1),32-42.

Clark, R. (1983). Reconsidering research on learning from media. Review of Educational Research, 53, 445-459.

Clements, D. and Nastasi, B. (1988). Social and cognitive interactions in educational computer environments. American Educational Research Journal, 25(1), 87-106.

Department of Employment, Education and Training (1994). A view of competence through a relational model. Higher Education Series Occasional Paper No. 7. Canberra: Australian Government Publishing Service.

Entwhistle, N. and Ramsden, P. (1982). Understanding student learning. Kent: Croom Helm Ltd.

Frampton, D. and Wharton, P. (1992). Power, control and interactivity: A substrate for interface design. Proceedings of the Information Technology for Training and Education Conference, p292-300. Brisbane: University of Queensland. 
Frampton, D. and Wharton, P. (1993). Interface design: Addressing the power motive in a user/hypermedium ecology. In Estes, N. and Thomas, M. (eds), Rethinking the roles of technology in education, Vol 1, 391-393. Cambridge, Massachusetts: Massachusetts Institute of Technology.

Gardner, H. (1983). Frames of mind: The theory of multiple intelligences. New York: Basic Books.

Glaser, R. (1984). Education and thinking: The role of knowledge. American Psychologist, 39(2), 93-104.

Greeno, J. (1989). A perspective on thinking. American Psychologist, February, 134-141.

Higher Education Council (1992a). Achieving quality. Canberra: Australian Government Publishing Service.

Higher Education Council (1992b). The quality of higher education: Discussion papers. Canberra: Australian Government Publishing Service.

Higher Education Council/ Australian Vice-Chancellor's Committee (1994). The enabling characteristics of undergraduate education: Discussion paper. Brisbane: Queensland University of Technology.

Hooper, S. and Hannafin, J. (1991). Psychological perspectives on emerging instructional techniques: A critical analysis. Educational Psychologist, 26(1), 69-95.

Jonassen, D. and Grabinger, R. (1989). Problems and issues in designing hypertext/hypermedia for learning. In Jonassen, D. and Mandl, H. (eds), Designing hypermedia for learning. Berlin: Springer-Verlag.

Kay, R. (1993/4). Understanding and evaluating measures of computer ability. Making a case for an alternative metric. Journal of Research on Computing in Education, 26(2), 270-284.

Kozma, R. (1991). Learning with media. Review of Educational Research, 61(2), 179-211.

Lave, J. (1988). Cognition in practice: Mind, mathematics and culture in everyday life. Cambridge University Press.

Marton, F. and Saljo, R. (1976). On qualitative differences in learning. I: Outcome and process; II: Outcome as a function of the learner's conception of the task. British Journal of Educational Psychology, 46, 4-11, 115-127.

McGuiness, C. (1993). Teaching thinking: New signs for theories of cognition. Educational Psychology, 13(3/4), 305-316.

Misanchuk, E. and Schwier, R. (1991). Interactive media audit trails: Approaches and issues. ERIC ED 334996.

Moses, I. and Trigwell, K. (1993). Teaching quality and quality of learning in professional courses. Higher Education Division: Evaluations and Investigations Program. Canberra: Australian Government Publishing Service.

O'Loughlin, M. (1992). Rethinking science education: Beyond Piagetian constructivism toward a sociocultural model of teaching and learning. Journal of Research in Science Teaching, 29(8), 791-820. 
Paul, R. and Nesich, G. (1992). A model for the national assessment of higher order thinking. Washington, DC: National Center for Education Statistics.

Pea, R. (1985). Beyond amplification: Using the computer to organise mental functioning. Educational Psychologist, 20(4), 167-182.

Pea, R. (1987a). Integrating human and computer intelligence. In Pea R and Sheingold K (eds), Mirrors of minds: Patterns of experience in educational computing. Norwood, NJ: Ablex.

Pea, R. (1987b). Socializing the knowledge transfer problem. International Journal of Educational Research, 11, 639-663.

Pea, R. (1992). Practices of distributed intelligence and designs for education. Technical Report \# 21. Evanston IL: Institute for the Learning Sciences, Northwestern University.

Perelman, L. (1992). School's out: Hyperlearning, the new technology, and the end of education. New York: William Morrow.

Perkins, D. (1993). Person-plus: A distributed view of thinking and learning. In Salomon, G. (ed), Distributed cognitions, p88-110. Cambridge: Cambridge University Press.

Perkins, D. and Salomon, G. (1989). Are cognitive skills context-bound? Educational Researcher, 18(1), 16-25.

Perkins, D., Jay, E. and Tishman, S. (1993). New conceptions of thinking: from ontology to education. Educational Psychologist, 28(1), 67-85.

Pogrow, S. (1985). HOTS: A computer-based approach. In Costa, A. (ed.), Developing Minds: A resource book for teaching thinking, p239-240. Alexandria, Va: Association for Supervision and Curriculum Development.

Presseisen, B. (1985). Thinking skills: Meanings and models. In Costa, A. (ed.), Developing Minds: A resource book for teaching thinking, p43-48. Alexandria, Va: Association for Supervision and Curriculum Development.

Richardson, J., Eysenck, M. and Warren, Piper D. (1987). Student learning: Research in education and cognitive psychology. Milton Keynes: SHRE and the Open University Press.

Ross, T. (1994, Autumn/Winter). Bloom and hypertext: Parallel taxonomies? Ed-Tech Review, 11-16.

Rowland, G. (1992). What do instructional designers actually do? An initial investigation of expert practice. Performance Improvement Quarterly, 5(2), 65-86.

Royer, J., Cisero, C. and Caro, M. (1993). Techniques and procedures for assessing cognitive skills. Review of Educational Research, 63(2), 201-243.

Salomon, G. (ed) (1993). Distributed cognitions. Cambridge: Cambridge University Press.

Schank, R. and Birnbaum, L. (1992). Can intelligence be enhanced? Technical Report \#33. Evanston, IL: The Institute for the Learning Sciences, Northwestern University. 
Schwarz, N. and Clore, G. (1988). How do I feel about it? The information function of affective states. In Fiedler, K. and Forgas, J. (eds), Affect, cognition and social behaviour. Toronto: C J Hogrefe.

Sternberg, R. (1986). Critical thinking: Its nature, measurement and improvement. ERIC 272882.

Twigg, C. (1994, July / August). The changing definition of learning. Educom Review.

Trigwell, K. and Prosser, M. (1991). Improving the quality of student learning: The influence of learning context and student approaches to learning on learning outcomes. Higher Education, 22, 251-266.

Warren, Piper (1993). Quality management in Universities. Vol 1. Canberra: Australian Government Publishing Service.

Author: David Frampton is Director of Educational Technology Services in the Information Services Division of Griffith University, Brisbane, Australia. His current research is concerned with the relationships between users' cognitions, particularly those of a higher order, and advanced technologies such as hypermedia used in information-seeking and learning tasks.

Please cite as: Frampton, D. (1994). Analysing cognitions in a hypermedia learning environment. Australian Journal of Educational Technology, 10(2), 8195. http:/ / www.ascilite.org.au/ajet/ajet10/frampton.html 